\title{
The frequency of the bony parameters of femoroacetabular impingement syndrome in young asymptomatic individuals: a computed tomography study
}

\author{
Menekşe Cengiz ${ }^{1}$ (D), Ayşe Keven² (D), Serra Öztürk ${ }^{1}$ (D), Hande Salim³ (D), Murat Gölpınar ${ }^{3}$ (D), \\ Kemal Gökkuşs (iD), Muzaffer Sindel ${ }^{1}$ (D) \\ ${ }^{1}$ Department of Anatomy, Faculty of Medicine, Akdeniz University, Antalya, Turkey \\ ${ }^{2}$ Department of Radiology, Faculty of Medicine, Akdeniz University, Antalya, Turkey \\ ${ }^{3}$ Department of Anatomy, Faculty of Medicine, Hitit University, Çorum, Turkey \\ ${ }^{4}$ Department of Orthopedics and Traumatology, Alanya Application and Research Center, Başkent University, Antalya, Turkey
}

\begin{abstract}
Objectives: Femoroacetabular impingement syndrome is a painful disorder of the hip formed by movements in the hip joint between the femoral head-neck junction and the acetabular edge. The aim of this study was to determine the prevalence of radiological femoroacetabular impingement syndrome findings in a young, asymptomatic Turkish population.

Methods: A total of 1000 abdominal pelvic CT images were collected from patients aged between 18-40 years. Measurements were taken on the CT images of the alpha angle and femoral head offset as signs of cam-type deformity, and of the acetabular version angle and center-edge angle as signs of pincer-type deformity.

Results: Femoroacetabular impingement syndrome was determined in $2.3 \%$ of the individuals. Pincer type deformity was determined in $56.5 \%$, being $83.3 \%$ in females and $47.1 \%$ in males. The cam-type deformity was present in $43.5 \%$ of all cases, being in $16.7 \%$ of the females and in $52.9 \%$ of the males. No difference was determined between the genders in respect of alpha angle which is $>55^{\circ}$. A head-neck offset which is $<8 \mathrm{~mm}$ was at a higher rate in females (13.3\%) than males. An acetabular anteversion angle which is $<15^{\circ}$ and centre-edge angle which is $>40^{\circ}$ was more in males than females at a rate of $11 \%$ and $25.2 \%$ respectively.

Conclusion: The results of this study showed that the incidence of cam-type deformity in the adult males and the incidence of pincer-type deformity in the adult females were lower in the asymptomatic Turkish population than previously reported in literature.
\end{abstract}

Keywords: cam deformity; computed tomography; femoroacetabular impingement syndrome; mixed deformity; pincer deformity Anatomy 2021;15(2):145-151 C2021 Turkish Society of Anatomy and Clinical Anatomy (TSACA)

\section{Introduction}

Femoral acetabular impingement syndrome (FAIS) has been defined as a painful hip disorder which results from abnormal contact between the femoral head-neck junction and the acetabular edge in hip joint movements, especially in flexion. ${ }^{[1]}$ In young adults, FAIS is the most common cause of hip pain and early degenerative changes. ${ }^{[2,3]}$ It has been previously described in as acetab- ular rim syndrome or cervico-acetabular impingement. ${ }^{[3,4]}$ Since this syndrome was defined by Ganz et al. ${ }^{[2]}$ in 2003, it has been the subject of continuous debate in the field of orthopedics. There are 3 different types of FAIS; cam type deformity (CD), pincer type deformity (PD), and mixed type deformity (MD) which is a combination of the $\mathrm{CD}$ and PD. Asymmetrical femoral head and neck junctionmay lead to CD impingement (femoral 
type: pistol grip). ${ }^{[-4]}$ In this deformity, the spherical property of the femoral head is lost, and the protrusion at the head-neck junction leads to a decrease in femoral head-neck offset. ${ }^{[5,6]}$ In PD (acetabular type), the femoral head is covered by the acetabulum focally or in a wide diameter. PD impingement occurs as a result of greater coverage than normal of the femoral head by an abnormally deep or retroverted acetabulum. ${ }^{[7]}$ The MD is characterized by morphological abnormalities in both the acetabulum and the femur head-neck junction. ${ }^{[2]}$

The prevalence of FAIS may change according to ethnicity and level of physical activities. ${ }^{[8]}$ Therefore, knowledge of the prevalence in an asymptomatic population will be useful both for patients and physicians for the implementation of the appropriate approach to the disease and the prevention of unnecessary arthroplasties. Only a limited number of studies have investigated the prevalence of FAIS in the asymptomatic Turkish population. ${ }^{[9]}$ Therefore, the aim of this study was to determine the incidence of FAIS on Computed Tomography (CT) images in a young adult asymptomatic Turkish population. The main hypothesis of the study was that FAIS incidence would be affected by demographic and ethnic factors and level of physical activities in different populations.

\section{Materials and Methods}

A retrospective evaluation was performed of pelvic CT images of patients, all aged 18-40 years, taken in the Radiology Department of Akdeniz University Medical Faculty Hospital between 2015 and 2020. CT images of the patients who had pelvic trauma, an orthopedic disorder, or an oncology history were not included in this study.

CT images taken at the upper level of the iliac crest to the proximal diaphragm of the femur were evaluated. The pelvic bone structure was examined in respect of cam, pincer, and mixed type deformities. Oblique, axial, and coronal images were obtained from multiplanar reformatted (MPR) images. Femoral head-neck junction distance, acetabular version angle, and center-edge angle were measured on these images.

The MDCT images were acquired by a 128 -detector CT device (Somatom Definition Edge, Siemens Healthcare, Erlangen, Germany) in the Radiology Department of Akdeniz University Medical Faculty Hospital. The image acquisition parameters were set as $16 \times 1.5 \mathrm{~mm}$ detector collimation, $120 \mathrm{kV}$ tube voltage, $0.5 \mathrm{sec}$ gantry rotation, and $180-220 \mathrm{~mA}$ tube flow. The images were reconstructed with a $1.5 \mathrm{~mm}$ reconstruction interval at a slice thickness of $1.5 \mathrm{~mm}$. The MDCT images sent from the picture archiving and communication system (Sectra Workstation IDS7; Sectra AB, Linköping, Sweden) through the network were evaluated on the workstation.

The alpha angle and femoral head offset were measured for determination of the CD, and acetabular version angle and center-edge angle were measured for the determination of PD. The alpha angle was formed in the oblique axial plane by centralization of the femoral neck center in the coronal plane on MPR images. For measurement of the alpha angle, a line was drawn along the long axis of the femoral neck to the center of the femoral head. A circle covering the subchondral bone was drawn. A second line was drawn to the center of the femoral head from the point where the femoral head emerges outside the circle. The angle between these two lines was defined as a alpha angle (Figure 1). An alpha angle value of $>55^{\circ}$ was evaluated as an indicator of FAIS. ${ }^{[10]}$

The femoral head-neck junction distance was measured in the oblique axial plane, where the alpha angle was obtained. The distance between the line drawn along the anterior of the femoral neck and the parallel line drawn from the widest anterior point of the femoral head, was measured as the femoral head-neck junction distance (Figure 2). A value $<8 \mathrm{~mm}$ was accepted as significant for FAIS. ${ }^{[11]}$

The acetabular version angle was evaluated on axial slices. On sections where the acetabulum was deepest a line was drawn at the level of the posterior boundaries of the acetabular labrum. The angle between the defined line and the line that was drawn between the anterior and posterior edges of the acetabulum is the acetabular version angle (Figure 3). An acetabular version angle $<15^{\circ}$ was accepted as abnormal. ${ }^{[12]}$

The centre-edge angle was measured on CT scanogram images. Firstly, a horizontal line was drawn passing through inferior borders of both ischial tuberosities. Then a vertical line was drawn perpendicular to this line from the centre of the femoral head. The angle between the perpendicular line passing through the center of the femoral head and the line drawn from the center of the femoral head to the lateral border of the acetabulum was considered as the central-edge angle (Figure 4). A centre-edge angle of $>40^{\circ}$ was accepted as abnormal. ${ }^{[13,14]}$

Data obtained in the study were analyzed statistically with Statistical Package for Social Sciences (SPSS Version 23, Armonk; NY, USA). Descriptive statistics were given as mean \pm standard deviation (SD), median (minimummaximum) and percentage (\%). Conformity of the data to normal distribution was assessed with the Shapiro Wilks 

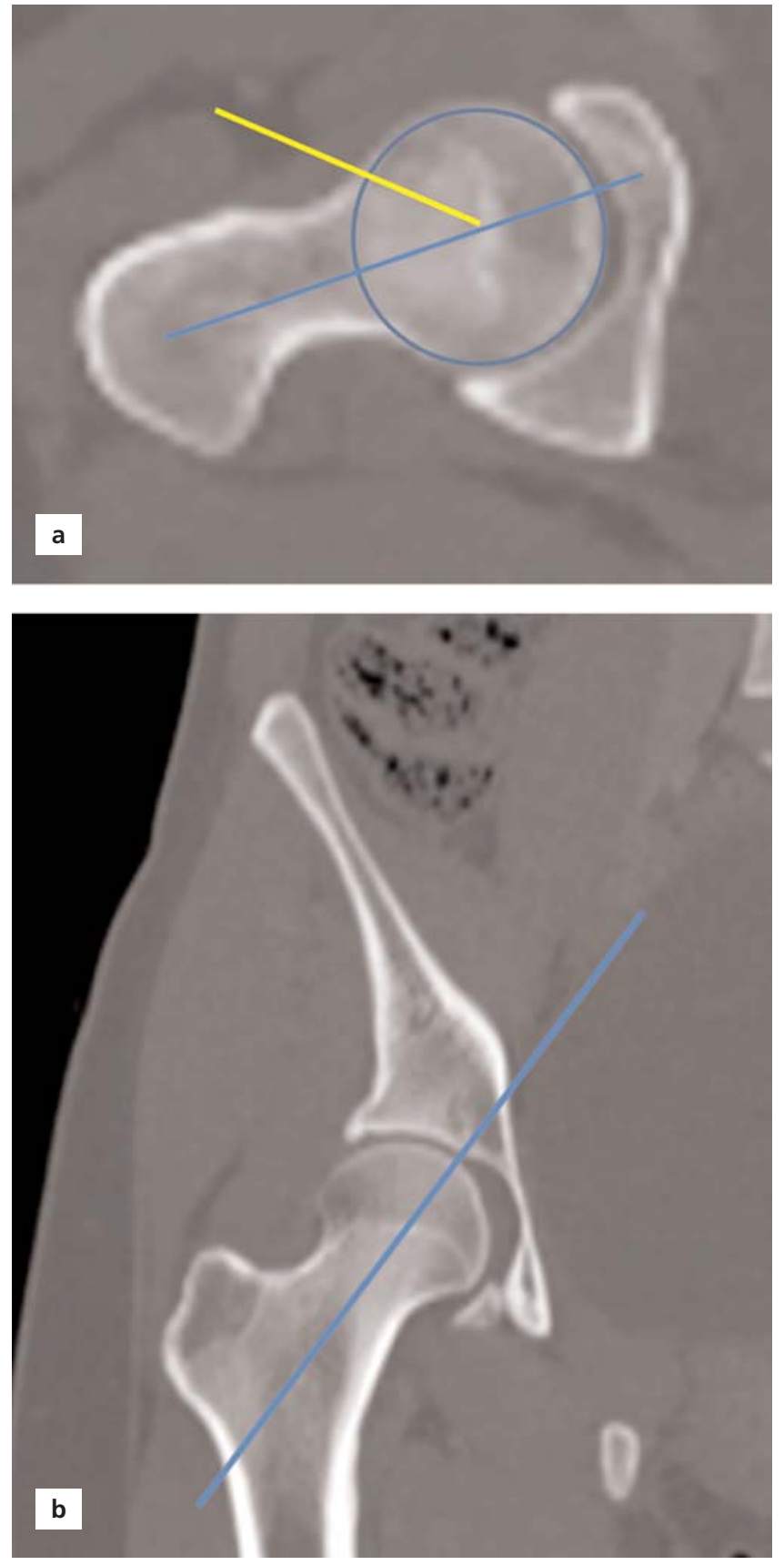

Figure 1. Measurement of the alpha angle. (a) Axial plane, (b) coronal plane.

test. In the analyses of relationships between categorical variables, Pearson Chi-square test and Fisher's Exact test were used. In the analysis of the difference between two groups, Student's t-test was applied when the data showed normal distribution and Mann-Whitney $U$ test was applied when distribution was abnormal. Spearman's correlation analysis was applied to evaluate relationships between ordinal variables or data not conforming to the

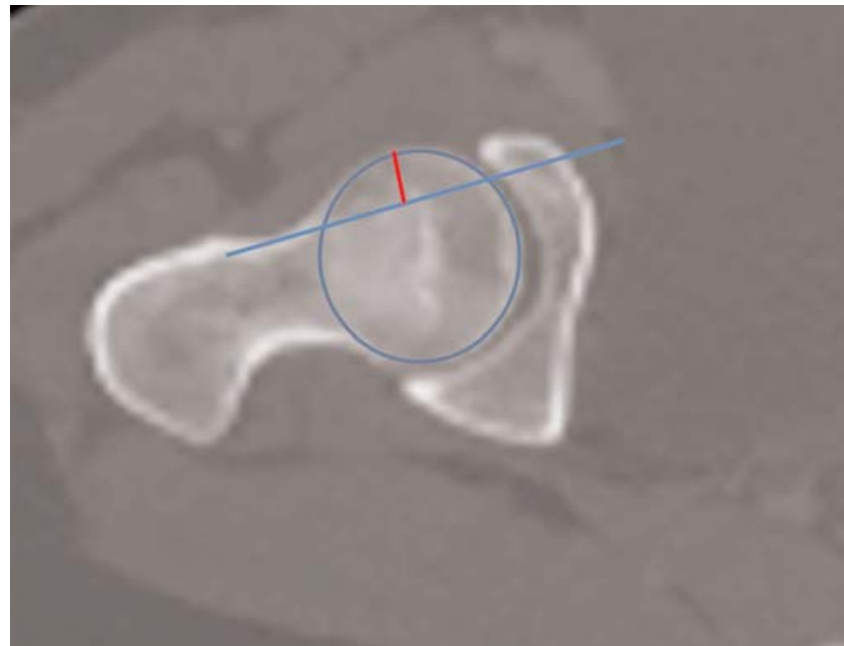

Figure 2. Measurement of the femur head-neck distance.

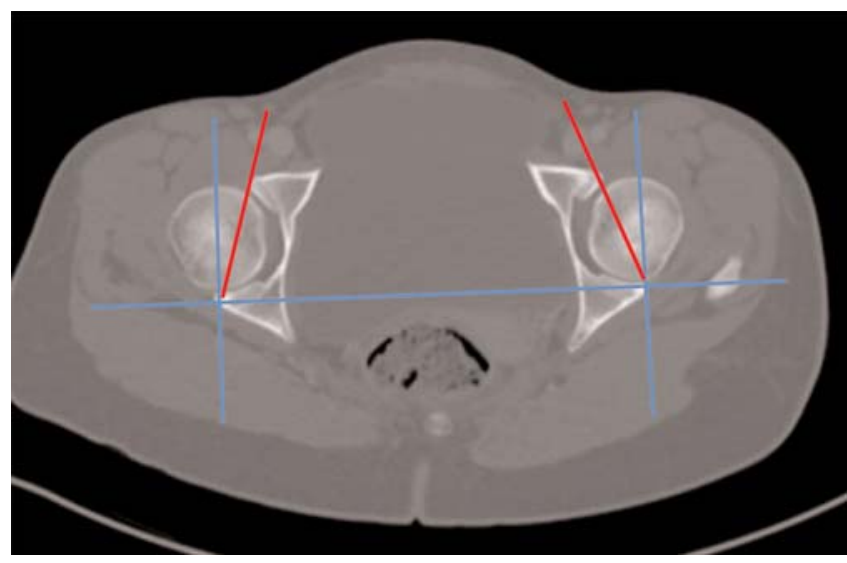

Figure 3. Measurement of the acetabular version angle.

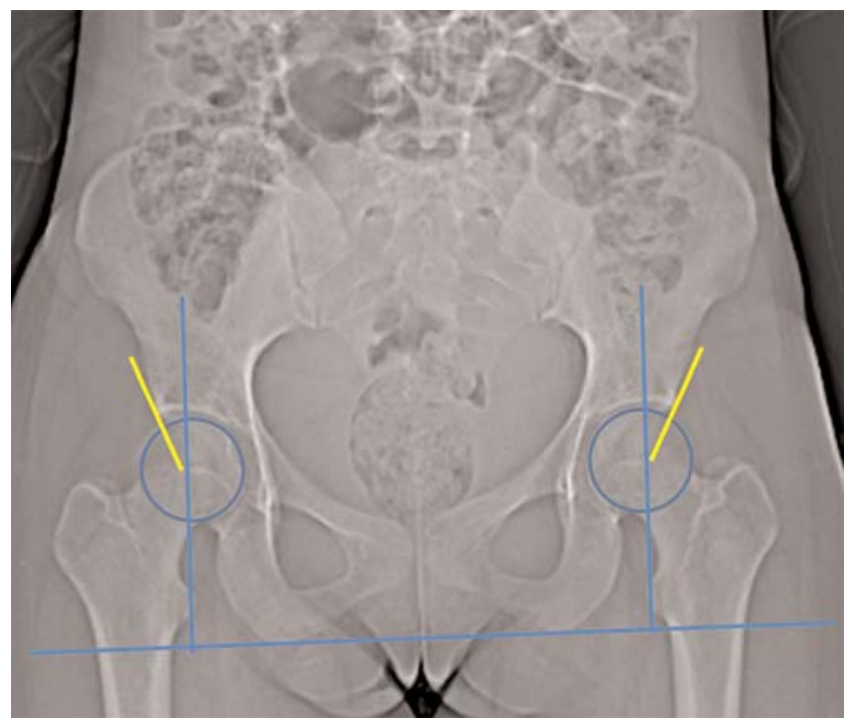

Figure 4. Measurement of the centre-edge angle. 

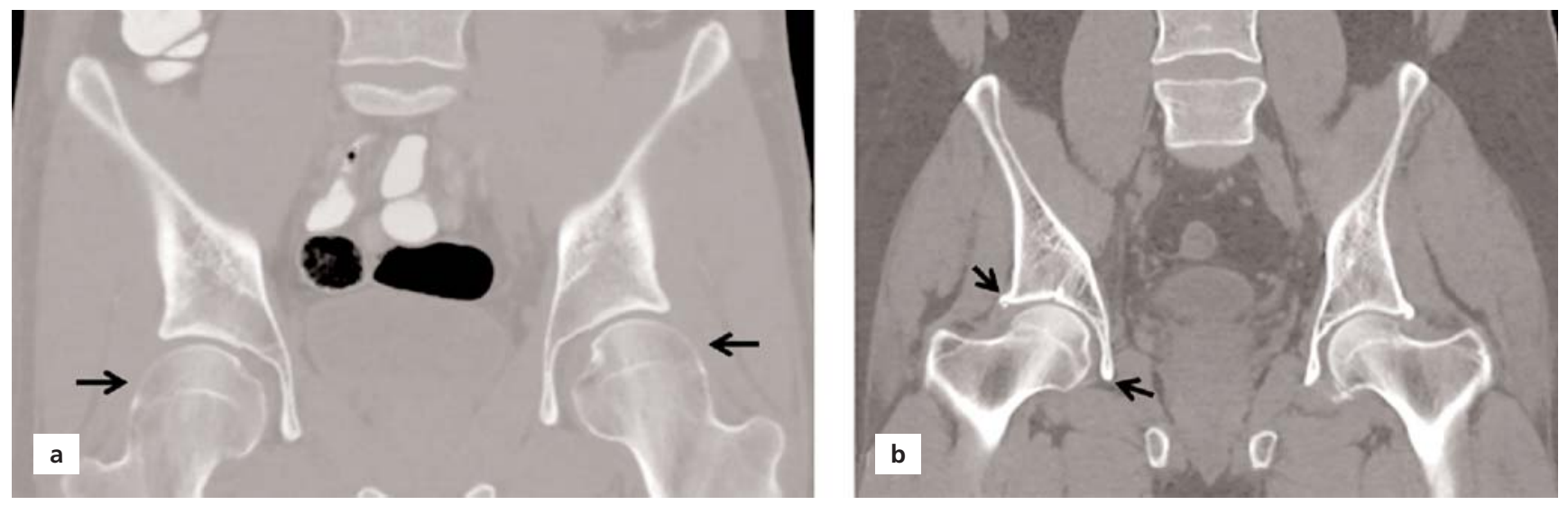

Figure 5. (a) Bilateral cam-type deformity (black arrows); (b) bilateral pincer-type deformity (black arrows)

normal distribution, and Pearson correlation analysis was applied to continuous variables with normal distribution. A p-value $<0.05$ was accepted as statistically significant. The incidence of male and female subjects was calculated by dividing the total number of hips for each gender by the total number of abnormal hips.

\section{Results}

Out of 1000 hips, 480 hips (48\%) were female and 520 hips $(52 \%)$ were male. FAIS was present in $2.3 \%$ of the hips examined. Thirteen (56.5\%) hips with FAS had PD and $10(43.5 \%)$ had CD (Figure 5). FAIS was identified in $1.3 \%$ of the females and in $3.3 \%$ of the males and the difference was statistically significant $(\mathrm{p}=0.033)$. FAIS was effecting the right hip joint in $2.4 \%$ and the left hip joint in $2.2 \%$. The difference between sides was not statistically significant $(\mathrm{p}=0.833)$. No significant difference was found when evaluated bilaterally $(\mathrm{p}>0.5)$. The PD was found in $83.3 \%$ of the females with FAIS and in $47.1 \%$ of males. $\mathrm{CD}$ was found in $16.7 \%$ of females and in $52.9 \%$ of males. The PD was present on the right side in $58.3 \%$ of the patients and on the left side in $54.5 \%$. The CD was present on the right side in $41.7 \%$ of the patients and on the left side in $45.5 \%$ (Table 1 ).

The summary of descriptive statistics of the radiological measurements of the patients were presented in the tables (Tables 2 and 3). No statistically significant difference was observed between the genders in respect of the alpha angle $(\mathrm{p}=0.712)$. In males, the head-neck offset measurement and center-edge angle were determined to be higher than those of females. The acetabular anteversion angles were statistically significantly higher in females than males $(\mathrm{p}<0.001)$. No significant difference was determined between the genders in respect of an alpha angle which is $>55^{\circ}(\mathrm{p}=0.110)$. Head-neck offset measurement which is $<8 \mathrm{~mm}$ was present at a higher rate in females $(13.3 \%)$ than males $(\mathrm{p}<0.001)$.
Acetabular version angle which is $<15^{\circ}$ and center-edge angle which is $>40^{\circ}$ was present at a higher rate in males $(11 \%$ and $25.2 \%$, respectively) than in females ( $\mathrm{p}=0.001$, $\mathrm{p}<0.001$ ). A significant positive weak correlation was found in all the hips between age and head-neck offset measurements $(\mathrm{r}=0.094, \mathrm{p}=0.003)$, acetabular anteversion angle $(r=0.199, p<0.001)$, and the center-edge angle $(r=0.153$, $\mathrm{p}<0.001$ ) (Tables 2 and 3 ).

\section{Discussion}

As a result of the impaired anatomic relationship in FAIS, there is unusual contact between the two sides of the cartilage and the labrum, and there may be degeneration in the hip joint in this process. This unusual form of contact can be determined with radiological tools such as conventional radiography, CT, and magnetic resonance imaging (MRI), taking measurements of some angles and distances using significant points in the bones. ${ }^{[2]}$ According to the 2016 Warwick Agreement, it was regarded that the morphology could be better characterized on cross-sectional images such as CT or MRI. ${ }^{[15]} \mathrm{CT}$ imaging has been reported to provide detailed visualization of the hip joint

Table 1

Patient characteristics.

\begin{tabular}{llc} 
& & n: 1000 \\
\hline \multirow{2}{*}{ Age (years) } & & $27.8 \pm 6.6(18-40)$ \\
\hline \multirow{2}{*}{ Fender } & Female & $480(48 \%)$ \\
\cline { 2 - 3 } & Male & $520(52 \%)$ \\
\hline \multirow{2}{*}{ FAIS Type } & Absent & $977(97.7 \%)$ \\
\cline { 2 - 3 } & Present & $23(2.3 \%)$ \\
\cline { 2 - 3 } & PINCER & $13(56.5 \%)$ \\
\hline
\end{tabular}

Results are presented as $\mathrm{n}(\%)$ and mean $\pm \mathrm{SD}$ values. 
Table 2

Comparison of the parameters according to gender. ${ }^{[1]}$

\begin{tabular}{|c|c|c|c|c|c|c|c|c|}
\hline \multirow{2}{*}{\multicolumn{2}{|c|}{ Measurements }} & \multicolumn{2}{|r|}{ Total } & \multicolumn{2}{|r|}{ Female } & \multicolumn{2}{|r|}{ Male } & \multirow[b]{2}{*}{ p-value } \\
\hline & & Mean \pm SD & Median (min-max) & Mean \pm SD & Median (min-max) & Mean \pm SD & Median (min-max) & \\
\hline \multirow{4}{*}{ 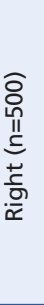 } & Alpha angle & $38.69 \pm 5.45$ & $38.1(15.2-63.2)$ & $38.22 \pm 5.19$ & $37.7(15.2-52.3)$ & $39.14 \pm 5.66$ & $38.45(24-63.2)$ & $\begin{array}{l}p=0.106 \\
z=-1.618\end{array}$ \\
\hline & Head-neck offset & $10.47 \pm 1.84$ & $10.55(4.5-15.3)$ & $9.81 \pm 1.73$ & $10(4.5-13.7)$ & $11.08 \pm 1.73$ & $11.2(5-15.3)$ & $\begin{array}{l}p<0.001 * \\
t=-8.228\end{array}$ \\
\hline & Acetabular anteversion & $21.11 \pm 3.55$ & $21(8.5-34.1)$ & $22.05 \pm 3.3$ & $22.1(13.1-34.1)$ & $20.24 \pm 3.55$ & $20.2(8.5-31.2)$ & $\begin{array}{c}p<0.001 \text { * } \\
t=5.886\end{array}$ \\
\hline & Centre-edge angle & $36.32 \pm 4.87$ & $36.3(19.1-51.9)$ & $35.17 \pm 4.63$ & $35(23.2-51.1)$ & $37.39 \pm 4.84$ & $37.3(19.1-51.9)$ & $\begin{array}{l}p<0.001 * \\
t=-5.231\end{array}$ \\
\hline \multirow{4}{*}{ 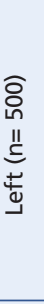 } & Alpha angle & $38.37 \pm 5.68$ & $37.7(20.9-62.1)$ & $38.65 \pm 5.69$ & $38(27.2-61.1)$ & $38.12 \pm 5.66$ & $37.2(20.9-62.1)$ & $\begin{array}{l}\mathrm{p}=0.285 \\
\mathrm{z}=-1.068\end{array}$ \\
\hline & Head-neck offset & $10.67 \pm 2.17$ & $10.75(6-37.4)$ & $10.11 \pm 1.56$ & $10.3(6-13.9)$ & $11.2 \pm 2.49$ & $11.3(6.4-37.4)$ & $\begin{array}{l}p<0.001 * \\
z=-6.458\end{array}$ \\
\hline & Acetabular anteversion & $20.03 \pm 3.89$ & $20.4(8.5-32.1)$ & $20.7 \pm 3.69$ & $21.1(9.9-30.3)$ & $19.42 \pm 3.97$ & $19.8(8.5-32.1)$ & $\begin{array}{l}p<0.001 * \\
z=-4.112\end{array}$ \\
\hline & Centre-edge angle & $35.88 \pm 4.87$ & $35.7(18.6-57.1)$ & $34.97 \pm 4.67$ & $34.8(21.8-49.2)$ & $36.71 \pm 4.91$ & $36.5(18.6-57.1)$ & $\begin{array}{l}\mathrm{p}<0.001 \text { * } \\
\mathrm{t}=-4.054\end{array}$ \\
\hline \multirow{4}{*}{ 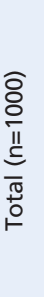 } & Alpha angle & $38.53 \pm 5.57$ & $37.9(15.2-63.2)$ & $38.43 \pm 5.45$ & $37.8(15.2-61.1)$ & $38.63 \pm 5.68$ & $38.1(20.9-63.2)$ & $\begin{array}{l}p=0.712 \\
z=-0.369\end{array}$ \\
\hline & Head-neck offset & $10.57 \pm 2.01$ & $10.65(4.5-37.4)$ & $9.96 \pm 1.65$ & $10.2(4.5-13.9)$ & $11.14 \pm 2.14$ & $11.2(5-37.4)$ & $\begin{array}{l}p<0.001 * \\
z=-9.946\end{array}$ \\
\hline & Acetabular anteversion & $20.57 \pm 3.76$ & $20.7(8.5-34.1)$ & $21.37 \pm 3.57$ & $21.45(9.9-34.1)$ & $19.83 \pm 3.79$ & $20(8.5-32.1)$ & $\begin{array}{c}p<0.001 * \\
t=6.618\end{array}$ \\
\hline & Centre-edge angle & $36.1 \pm 4.87$ & $36(18.6-57.1)$ & $35.07 \pm 4.65$ & $34.9(21.8-51.1)$ & $37.05 \pm 4.88$ & $37(18.6-57.1)$ & $\begin{array}{l}p<0.001 \text { * } \\
t=-6.558\end{array}$ \\
\hline
\end{tabular}

Mann-Whitney U test, Student's t-test. ${ }^{*} \mathrm{p}<0.001$.

segments such as the inferoposterior and posterolateral hip joint which may be difficult to define on radiographs. ${ }^{[16]} \mathrm{In}$ addition, CT scanning can provide information about the proximal femoral version for the characterization of extraarticular deformity and impingement. ${ }^{[17]}$ In several studies, researchers have examined the parameters and prevalence

Table 3

Comparison of the parameters according to gender. ${ }^{[2]}$.

\begin{tabular}{|c|c|c|c|c|c|}
\hline \multicolumn{2}{|c|}{ Measurements } & \multirow{2}{*}{$\begin{array}{l}\text { Total } \\
\mathbf{n}(\%)\end{array}$} & \multirow{2}{*}{$\begin{array}{c}\begin{array}{c}\text { Female } \\
\text { n (\%) }\end{array} \\
0(0)\end{array}$} & \multirow{2}{*}{$\begin{array}{l}\begin{array}{c}\text { Male } \\
\text { n (\%) }\end{array} \\
3(1.2)\end{array}$} & \multirow{2}{*}{$\frac{\mathbf{p} \text {-value }}{0.250}$} \\
\hline $\bar{\delta}$ & Alpha angle $>55^{\circ}$ & & & & \\
\hline$\stackrel{L}{\check{c}}$ & Head-neck offset $<8 \mathrm{~mm}$ & $54(10.8)$ & $42(17.5)$ & $12(4.6)$ & $<0.001$ * \\
\hline$\underline{ت}$ & Acetabular anteversion $<15^{\circ}$ & $24(4.8)$ & $4(1.7)$ & $20(7.7)$ & $0.002^{*}$ \\
\hline a & Centre-edge $>40^{\circ}$ & $105(21)$ & $36(15)$ & $69(26.5)$ & $0.002^{*}$ \\
\hline \multirow{4}{*}{ 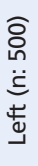 } & Alpha angle $>55^{\circ}$ & $7(1.4)$ & $2(0.8)$ & $5(1.9)$ & 0.452 \\
\hline & Head-neck offset $<8 \mathrm{~mm}$ & $35(7)$ & $22(9.2)$ & $13(5)$ & 0.068 \\
\hline & Acetabular anteversion $<15^{\circ}$ & $57(11.4)$ & $20(8.3)$ & $37(14.2)$ & 0.038 \\
\hline & Centre-edge $>40^{\circ}$ & $96(19.2)$ & $34(14.2)$ & $62(23.8)$ & 0.006 \\
\hline \multirow{4}{*}{ 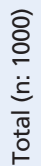 } & Alpha angle $>55^{\circ}$ & $10(1)$ & $2(0.4)$ & $8(1.5)$ & 0.110 \\
\hline & Head-neck offset $<8$ mm & $89(8.9)$ & $64(13.3)$ & $25(4.8)$ & $<0.001^{*}$ \\
\hline & Acetabular anteversion $<15^{\circ}$ & $81(8.1)$ & $24(5)$ & $57(11)$ & $0.001 *$ \\
\hline & Centre-edge $>40^{\circ}$ & $201(20.1)$ & 70 (14.6) & $131(25.2)$ & $<0.001 *$ \\
\hline
\end{tabular}

Pearson chi-square test, Fisher's exact test. ${ }^{*} p<0.001$. 
of FAIS on conventional radiography-based, CT, and MR images in large populations. ${ }^{[9,18-20]}$

The prevalence of FAIS in asymptomatic individuals in the Turkish population was found to be $29.6 \%$. Polat et al. ${ }^{[9]}$ reported FAIS at the rate of $30 \%$ in Turkish males. Fukushima et al. ${ }^{[20]}$ concluded that FAIS cases were very rare in the Japanese population. Frank et al. ${ }^{[2]}$ reported the prevalence of cam deformity was $37 \%$ and the prevalence of pincer deformity was $67 \%$. Interestingly, there was an almost 3:1 ratio of cam deformity in the athletic population compared with the nonathletic people.

Laborie et al ${ }^{[18]}$ reported the prevalence of CD and PD in males to be $21.5 \%$ and $23.4 \%$, respectively. In females, PD impingement was reported at the rate of $11 \%$ by Laborie et al ${ }^{[18]}$ and $11.6 \%$ by Polat et al ${ }^{[9]}$ In the current study, the CD was determined at $16.7 \%$ and PD at $83.3 \%$ in females. Gosvig et al ${ }^{[19]}$ found CD prevalence in males to be $17 \%$. Polat et al ${ }^{[9]}$ reported CD prevalence as $30.8 \%$ and $\mathrm{PD}$ as $9.3 \%$. In the current study, PD in the male population was determined to be $47.1 \%$, and CD, $52.9 \%$.

Reichenbach et al. ${ }^{[2]}$ examined CD prevalence in young males and reported that $24 \%$ of the males had CD. CD impingement is generally seen in young males and PD impingement in middle-aged females. ${ }^{[8]}$ In studies of asymptomatic individuals, the $\mathrm{CD}$ has been reported at rates varying between $9 \%$ and $25 \%$ in males and between $3 \%$ and $10 \%$ in females. ${ }^{[23]}$ In a by Gosvig et al. ${ }^{[19]} \mathrm{CD}$ impingement morphology was determined in $17 \%$ of males and $4 \%$ of females. In a study of the CT images of a young population, Chakraverty et al. ${ }^{[2]}$ examined FAIS prevalence and reported MD at the rate of $22 \%$. No cases of MD were observed in our study.

Tannenbaum et al. ${ }^{[25]}$ found a higher rate of acetabular retroversion in women compared to men, similar to our findings. In another study, alpha angle was found to be $45.6^{\circ}$ in females and $48^{\circ}$ in males, the acetabular version angle was $16.8^{\circ}$ in females and $16.2^{\circ}$ in males, and the center-edge angle was $37^{\circ}$ in females and $37.4^{\circ}$ in males. ${ }^{[14]}$ In the CT-based study of Jung et al., ${ }^{[26]}$ the mean alpha angle was reported as $59.1^{\circ}$ in 215 male hip joints and $45.4^{\circ}$ in 540 female hip joint. These results demonstrated that $\mathrm{CD}$ was not uncommon in an asymptomatic population group. Jung et al. ${ }^{[26]}$ revealed the mean alpha angle as $38.6^{\circ}$ in men and $38.4^{\circ}$ in women. These findings are similar to our findings.

Our study showed that the incidence of FAIS was $2.3 \%$. The mean alpha angle was $37.8^{\circ}$ in women and $38.1^{\circ}$ in men, and there was no significant difference between the genders. Head-neck deviation and centeredge angle values were higher in men, and acetabular anteversion angles were higher in women. In our study, the center-edge angle was measured as $35^{\circ}$ in women and $37^{\circ}$ in men. As a result, the alpha angle was found to be extremely low in this study compared to other studies. Since the pelvis is horizontal during CT measurements, we think that this will affect the acetabulum version angle. We believe that in Turkish society, the acetabulum is associated with more lordosis, especially in women. According to the results obtained in this study, a slight anteverted position was observed in the Turkish population. The incidence of $\mathrm{CD}$ in the adult male asymptomatic population and the incidence of PD in the adult female asymptomatic population were higher than the rates reported in the literature. The incidence of pathological acetabular version angle was higher in women. There was no significant difference between men and women in terms of alpha angle measurements.

\section{Conclusion}

In conclusion, our study is one of the most comprehensive studies conducted in the Turkish population. We think that the alpha angle is a controversial parameter in the diagnosis of cam-type deformity. On the other hand, head-neck offset measurement and median margin angle were higher in males and higher in females in acetabular version angles. The fact that our study results differ from previous CT studies may be due to genetic factors and the difference at the level of physical activity done during childhood and adolescence.

\section{Conflict of Interest}

The authors declare that they have no related conflicts of interest.

\section{Author Contributions}

MC: investigation, data collection, data analysis; AK: data collection, data analysis; SO: data analysis, manuscript writing, manuscript editing; HS: data analysis, manuscript editing; MG: manuscript writing, manuscript editing; KG: project development, data collection; MS: project development, manuscript editing, supervision.

\section{Ethics Approval}

All protocols were approved by Akdeniz University Clinical Research Ethics Committee and carried out under the supervision of them (Date-Number of the ethical approval: 24.07.2019-732). Approval from the Institutional Review Board was obtained and in keeping with the policies for a retrospective review, informed consent was not required.

\section{Funding}

This research did not receive any grants from any funding agency in the public, commercial or not-for-profit sectors. 


\section{References}

1. Harris WH. Etiology of osteoarthritis of the hip. Clin Orthop Relat Res 1986;(213):20-33.

2. Ganz R, Parvizi J, Beck M, Leunig M, Nötzli H, Siebenrock KA. Femoroacetabular impingement: a cause for osteoarthritis of the hip. Clin Orthop Relat Res 2003;(417):112-20.

3. Klaue K, Durnin C, Ganz R. The acetabular rim syndrome. A clinical presentation of dysplasia of the hip. J Bone Joint Surg Br 1991;73:4239.

4. Ganz R, Bamert P, Hausner P, Isler B, Vrevc F. Cervico-acetabular impingement after femoral neck fracture. Unfallchirurg 1991;94:172 5.

5. Ito K, Minka 2nd MA, Leunig M, Werlen S, Ganz R. Femoroacetabular impingement and the cam-effect: a MRI-based quantitative anatomical study of the femoral head-neck offset. J Bone Joint Surg Br 2001;83:171-6.

6. Agricola R, Heijboer MP, Ginai AZ, Roels P, Zadpoor AA, Verhaar JA, Weinans $\mathrm{H}$, Waarsing JH. A cam deformity is gradually acquired during skeletal maturation in adolescent and young male soccer players: a prospective study with minimum 2-year follow-up. Am J Sports Med 2014;42:798-806.

7. Tannast M, Siebenrock KA, Anderson SE. Femoroacetabular impingement: radiographic diagnosis--what the radiologist should know. AJR Am J Roentgenol 2007;188:1540-52.

8. Van Klij P, Heerey J, Waarsing JH, Agricola R. The prevalence of cam and pincer morphology and its association with development of hip osteoarthritis. J Orthop Sports Phys Ther 2018;48:230-8.

9. Polat G, Şahin K, Arzu U, Kendirci AŞ, Aşık M. Prevalence of asymptomatic femoroacetabular impingement in Turkey; cross sectional study. Acta Orthop Traumatol Turc 2018;52:49-53.

10. Nötzli HP, Wyss TF, Stoecklin CH, Schmid MR, Treiber K, Hodler $\mathrm{J}$. The contour of the femoral head-neck junction as a predictor for the risk of anterior impingement. J Bone Joint Surg Br 2002;84:556-60.

11. Wenger DE, Kendell KR, Miner MR, Trousdale RT. Acetabular labral tears rarely occur in the absence of bony abnormalities. Clin Orthop Relat Res 2004;(426):145-50.

12. Tönnis D, Heinecke A. Current concepts review-acetabular and femoral anteversion: relationship with osteoarthritis of the hip. J Bone Joint Surg Am 1999;81:1747-70.11.

13. Delaunay S, Dussault R, Kaplan P, Alford B. Radiographic measurements of dysplastic adult hips. Skeletal Radiol 1997;26:75-81.

14. Kim J, Choi J-A, Lee E, Lee KR. Prevalence of imaging features on CT thought to be associated with femoroacetabular impingement: a retrospective analysis of 473 asymptomatic adult hip joints. AJR Am J Roentgenol 2015;205:W100-5.

15. Griffin DR, Dickenson EJ, O’Donnell J, Agricola R, Awan T, Beck M, Clohisy JC, Dijkstra HP, Falvey E, Gimpel M, Hinman RS,

ORCID ID:

M. Cengiz 0000-0003-2549-7941; A. Keven 0000-0002-1662-8586; S. Öztürk 0000-0003-1002-0059; H. Salim 0000-0002-7231-9526; M. Golpinar 0000-0001-9419-5993; K. Gökkuş 0000-0002-4916-3471; M. Sindel 0000-0002-6594-1325

deomed。
Hölmich P, Kassarjian A, Martin HD, Martin R, Mather RC, Philippon MJ, Reiman MP, Takla A, Thorborg K, Walker S, Weir A, Bennell KL. The Warwick Agreement on femoroacetabular impingement syndrome (FAI syndrome): an international consensus statement. Br J Sports Med 2016;50:1169-76.

16. Huang BK, Tan W, Scherer KF, Rennie W, Chung CB, Bancroft LW. Standard and advanced imaging of hip osteoarthritis. What the radiologist should know. Semin Musculoskelet Radiol 2019;23:289_ 303.

17. Griffin JW, Weber AE, Kuhns B, Lewis P, Nho SJ. Imaging in hip arthroscopy for femoroacetabular impingement: a comprehensive approach. Clin Sports Med 2016;35:331-44.

18. Laborie LB, Lehmann TG, Engesæter IØ, Eastwood DM, Engesæter LB, Rosendahl K. Prevalence of radiographic findings thought to be associated with femoroacetabular impingement in a population-based cohort of 2081 healthy young adults. Radiology 2011;260:494-502.

19. Gosvig K, Jacobsen S, Sonne-Holm S, Gebuhr P. The prevalence of cam-type deformity of the hip joint: a survey of 4151 subjects of the Copenhagen osteoarthritis study. Acta Radiol 2008;49:436-41.

20. Fukushima K, Uchiyama K, Takahira N, Moriya M, Yamamoto T, Itoman M, Takaso M. Prevalence of radiographic findings of femoroacetabular impingement in the Japanese population. J Orthop Surg Res 2014;9:1-6.

21. Frank JM, Harris JD, Erickson BJ, Slikker W 3rd, Bush-Joseph CA, Salata MJ, Nho SJ. Prevalence of femoroacetabular impingement imaging findings in asymptomatic volunteers: a systematic review. Arthroscopy 2015;31:1199-204.

22. Reichenbach S, Jüni P, Werlen S, Nüesch E, Pfirrmann CW, Trelle S, Odermatt A, Hofstetter W, Ganz R, Leunig M. Prevalence of camtype deformity on hip magnetic resonance imaging in young males: a cross-sectional study. Arthritis Care Res (Hoboken) 2010;62:1319-27.

23. Gosvig KK, Jacobsen S, Sonne-Holm S, Palm H, Troelsen A. Prevalence of malformations of the hip joint and their relationship to sex, groin pain, and risk of osteoarthritis: a population-based survey. J Bone Joint Surg Am 2010;92:1162-9.

24. Chakraverty JK, Sullivan C, Gan C, Narayanaswamy S, Kamath S. Cam and pincer femoroacetabular impingement: CT findings of features resembling femoroacetabular impingement in a young population without symptoms. AJR Am J Roentgenol 2013;200:389-95.

25. Tannenbaum EP, Zhang P, Maratt JD, Gombera MM, Holcombe SA, Wang SC, Bedi A, Goulet JA. A computed tomography study of gender differences in acetabular version and morphology: implications for femoroacetabular impingement. Arthroscopy 2015;31:1247-54.

26. Jung KA, Restrepo C, Hellman M, AbdelSalam H, Morrison W, Parvizi J. The prevalence of cam-type femoroacetabular deformity in asymptomatic adults. J Bone Joint Surg Br 2011;93:1303-7.

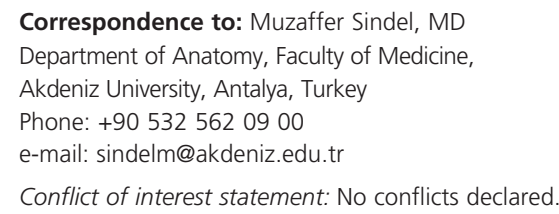

This is an open access article distributed under the terms of the Creative Commons Attribution-NonCommercial-NoDerivs 4.0 Unported (CC BY-NCND4.0) Licence (http://creativecommons.org/licenses/by-nc-nd/4.0/) which permits unrestricted noncommercial use, distribution, and reproduction in any medium, provided the original work is properly cited. How to cite this article: Cengiz M, Keven A, Öztürk S, Salim H, Golpinar M, Gökkuş K, Sindel M. Anatomic correlation of common fibular nerve palsy encountered after short leg casts. Anatomy 2021;15(2):145-151. 